\title{
Aansluiting van de studie geneeskunde op vervolg- opleidingen: een interviewstudie onder arts-assistenten en opleiders van medische specialismen
}

H.E. Westerveld, L. Bos-Onderstal, E.W.M.T. ter Braak, H.L. Hendrix, M.B. Lagaaij, Th.B. Voorn, Th.J. ten Cate

\section{Samenvatting}

Inleiding: Dit artikel beschrijft de resultaten van een exploratieve studie naar mogelijkheden om de studie geneeskunde en de vervolgopleidingen beter op elkaar te laten aansluiten.

Materiaal en methoden: 30 Opleiders en 18 arts-assistenten-in-opleiding in de opleidingsregio's Utrecht, Amsterdam (AMC) en Leiden werden geïnterviewd. Er werd gevraagd naar de noodzaak tot verbetering van een twintigtal klinische competenties. Daarnaast werd gevraagd naar suggesties voor inhoud en vormgeving van onderwijs in een hypothetisch 'extra jaar' gericht op verbetering van de aansluiting.

Resultaten: Onderwerpen waarvan het meest frequent wordt aangegeven dat een betere beheersing gewenst is bij de aanvang van de specialistenopleiding zijn farmacotherapie, juridische kennis, gestructureerd probleemoplossen, het omgaan met klachten en het onderscheiden van hoofd-en bijzaken. Het kunnen aanvragen van intercollegiale consulten en het beheersen van vaardigheden wordt het minst genoemd als gebied waarop verbetering wenslijk is. Het valt op dat vooral verbetering gewenst wordt in algemene vaardigheden, zoals het onderscheiden van hoofd- en bijzaken, het formuleren van de essentie, prioriteren, gestructureerd werken, communicatieve vaardigheden en verslagleggen. Ook valt op dat veel van de voorstellen voor de invulling van aanvullend onderwijs gericht zijn op het ontwikkelen van verantwoordelijkheid en zelfstandigheid. Voorts blijkt er geen of nauwelijks verschil te zijn in de oordelen van assistenten en opleiders, in de verschillende regio's en in verschillende typen ziekenhuizen.

Conclusie: De studie levert veel suggesties op die bruikbaar zijn voor de invulling van het laatste jaar van de studie geneeskunde. Algemene vaardigheden en zelfstandig leren werken scoren hoog. (Westerveld HE, Bos-Onderstal L, Braak EWMT ter, Hendrix HL, Lagaaij MB, Voorn ThB, Cate ThJ ten. Aansluiting van de studie geneeskunde op vervolgopleidingen: een interviewstudie onder arts-assistenten en opleiders van medische specialismen. Tijdschrift voor Medisch Onderwijs 2004;23(1):15-22.)

\section{Inleiding}

De eerste aanbeveling uit het rapport 'De zorg van morgen' luidt: “Een naadloze aansluiting tussen de initiële opleiding en de vervolgopleidingen moet worden gerealiseerd."1 Voor het ontwikkelen van een visie op de structuur, inhoud en lengte van het gehele medische opleidingscontinuüm, waarin de studie geneeskunde en de vervolgopleidingen goed op elkaar aansluiten, is informatie-uitwisseling tussen de betrokken partijen nodig. ${ }^{2-6}$ Het huidige onderzoek is opgezet om een indruk te krijgen van de visie van opleiders van medische specialismen en van arts-assistenten op het niveau van de basisarts bij aanvang van de specialisatie en op de mogelijkheden tot verbetering hiervan. 


\section{Materiaal en methoden}

Het betreft een exploratieve studie naar ideeën en mogelijkheden om de studie geneeskunde beter af te stemmen op de opleiding tot medisch specialist.

\section{Fasering}

In de eerste fase van het onderzoek (maart-juni 2002) zijn opleiders uit het AMC, het UMC Utrecht en geaffilieerde ziekenhuizen geïnterviewd. In een tweede fase (november-december 2002) is het onderzoek uitgebreid met opleiders en artsassistenten uit het LUMC en geaffilieerde ziekenhuizen en met arts-assistenten uit het UMC Utrecht.

\section{Interviews}

In gestructureerde, één uur durende interviews is voor twintig klinische competenties gevraagd naar de noodzaak tot verbetering van het niveau bij de aanvang van de specialistenopleiding (zie tabel 1). De antwoorden zijn aangegeven op een 4-punts schaal met de volgende waarden:

$1=\mathrm{Er}$ is geen verbetering nodig, omdat de studenten bij aanvang van de specialisatie dit onderwerp voldoende beheersen of omdat het beter tijdens de specialisatie geleerd kan worden.

2 = Verbetering is gewenst met lage prioriteit.

3 = Verbetering is gewenst met middelmatige prioriteit.

4 = Verbetering is gewenst met hoge prioriteit.

De twintig competenties werden in enkele ronden geformuleerd door dr. H.E. Westerveld, dr. E.W.M.T. ter Braak en prof.dr. Th.J. ten Cate. Hiervoor werd niet het 'Raamplan 2001 Artsopleiding'7 als uitgangspunt gekozen, omdat gezocht werd naar activiteiten die duidelijker van her- kenbaar praktische waarde voor de artsassistent zouden zijn. Het raamplan is hiervoor te algemeen geformuleerd, hoewel sommige items goede overlap vertonen. Tevens is per competentiegebied een open vraag gesteld naar suggesties voor verbetering.

In de tweede fase van het onderzoek, waarin opleiders en arts-assistenten uit het LUMC en arts-assistenten uit het UMC Utrecht geïnterviewd werden, is tevens specifiek gevraagd naar anatomische kennis. Na afloop van het gestructureerde deel van het interview is aan alle geïnterviewden gevraagd hoe zij een (hypothetisch) extra jaar studie, dat erop gericht zou zijn basisartsen beter toegerust aan de betreffende specialisatie te laten beginnen, zouden invullen. Om politieke discussies tijdens het interview over eventuele verkorting van het medisch opleidingscontinuüm te vermijden en om alleen inhoudelijke aspecten aan bod te laten komen is gekozen voor de formulering 'extra jaar'.

\section{Geïnterviewde opleiders en arts-assistenten}

Dertig academische en perifere opleiders van 10 disciplines uit het AMC, het UMC Utrecht en het LUMC en hun geaffilieerde ziekenhuizen zijn geïnterviewd. Er is een selectie gemaakt van opleidingen op basis van de grootte van het vak, de relevantie voor de huisarts en het aantal nieuwe registraties voor dat vak in 1999 op basis van gegevens van de KNMG. Het betrof de volgende specialismen: interne geneeskunde, chirurgie, huisartsgeneeskunde, gynaecologie/verloskunde, kindergeneeskunde, neurologie, psychiatrie, dermatologie, radiologie en sociale geneeskunde/ public health.

Interviews zijn verricht in de volgende ziekenhuizen: AMC, Slotervaart Zieken- 
huis en OLVG (Amsterdam), LUMC (Leiden), Ziekenhuis Bronovo, Leyenburg Ziekenhuis en Parnassia Psycho-Medisch Centrum (Den Haag), UMC Utrecht, Antonius Ziekenhuis (Nieuwegein), Meander Medisch Centrum (Amersfoort), Elisabeth Ziekenhuis (Tilburg) en Ziekenhuis Meerkanten (Ermelo), en in een huisartspraktijk (Den Haag).

Hetzelfde interview is tevens voorgelegd aan 18 arts-assistenten in het UMC Utrecht, het LUMC en hieraan geaffilieerde ziekenhuizen. Arts-assistenten werd gevraagd te reflecteren op hun eigen situatie gedurende de eerste 3 maanden van hun opleiding. Er is voor gekozen om arts-assistenten te interviewen die met het tweede jaar van hun vervolgopleiding bezig waren. Deze termijn is genomen in de veronderstelling dat arts-assistenten dan enerzijds voldoende afstand hebben tot de beginperiode van hun opleiding om erop te kunnen reflecteren en anderzijds voldoende zicht zouden hebben op het totaal van de opleiding om de problemen van het eerste deel van de opleiding in perspectief te zien. Verder zou het opleidingsbegin nog voldoende kort geleden zijn om het zich goed te kunnen herinneren. De opleiders hebben de arts-assistenten aangewezen. Er is gestreefd naar een gelijkmatige verdeling van de geïnterviewden over academische en perifere ziekenhuizen. Waar in de regio Utrecht een perifere opleider is geïnterviewd, is in de andere regio's een academische opleider geïnterviewd.

\section{Dataweergave}

De scores op de 4-punts schaal naar noodzaak tot verbetering zijn weergegeven als gemiddelde \pm sd. Er is tevens een totaal score berekend per geïnterviewde, gevormd door de som van de afzonderlijke scores op de 20 vragen. Wanneer een vraag voor een bepaald specialisme niet relevant was, is die vraag voor dat specialisme niet meegerekend.

\section{Statistiek}

Verschillen in scores op de 4-punts schaal tussen opleiders en arts-assistenten zijn getoetst met non-parametrische toetsen voor gepaarde data (Wilcoxon signed ranks test). Verschillen tussen academische en perifere ziekenhuizen en tussen de regio's Amsterdam, Leiden en Utrecht zijn getoetst met non-parametrische toetsen voor niet-gepaarde data (Mann Whitney-U testen). Er is Bonferroni-correctie toegepast. Tevens is een one-way Anova uitgevoerd om mogelijke verschillen te detecteren tussen de volgende groepen: opleiders Utrecht, opleiders Leiden, opleiders Amsterdam, arts-assistenten Utrecht en artsassistenten Leiden.

\section{Resultaten}

\section{Algemeen}

De bereidheid van de opleiders en de artsassistenten om mee te werken aan de interviews was groot. Op één na alle benaderde opleiders en alle arts-assistenten hebben hun medewerking verleend. De interviews waren klinisch georiënteerd. Dit maakte verscheidene vragen van het interview minder relevant voor de sociale geneeskunde. Om die reden zijn de interviews van de sociale geneeskunde niet meegenomen in de analyses van het gestructureerde deel van het interview. De antwoorden op de open vraag over invulling van een extra jaar zijn wel meegenomen.

\section{Scores per vraag}

In tabel 1 zijn per vraag de gemiddelde scores met betrekking tot de noodzaak tot verbetering van 20 klinische competenties van een basisarts weergegeven. Er waren geen significante verschillen tussen oplei- 
ders en arts-assistenten, tussen academische en perifere opleiders of tussen academische en perifere assistenten. Dit geldt zowel voor de totale groep als voor de afzonderlijke regio's.

In het tweede deel van de studie, waarin opleiders en arts-assistenten uit het LUMC en geaffilieerde ziekenhuizen geïnterviewd zijn en arts-assistenten uit het UMC Utrecht en geaffilieerde ziekenhuizen, is tevens gevraagd naar anatomische kennis. Deze scoort gemiddeld 1.96 voor assistenten en opleiders tezamen. Opvallend is dat één derde van de ondervraagde arts-assistenten vroeger student-assistent anatomie geweest is. Hierdoor wordt de noodzaak tot verbetering van het niveau van de ana- tomische kennis door deze arts-assistenten lager aangegeven dan wanneer zij geen student-assistent waren geweest.

\section{Totaal score}

De gemiddelde score over alle items ( $\pm \mathrm{sd}$ ) bedroeg voor opleiders $2.09 \pm 0.46$ en voor arts-assistenten $1.83 \pm 0.44$. Het verschil is significant $(\mathrm{P}=0.04)$. Beide groepen voelen dus een noodzaak tot verbetering van de basisopleiding, maar met een (over alle items gezien) lage prioriteit, waarbij de assistenten de minste urgentie voelen.

\section{Suggesties voor verbetering}

Per vraag zijn veel suggesties voor verbetering gedaan, zowel inhoudelijk als qua

Tabel 1. Noodzaak tot verbetering van 20 klinische competenties (gemiddelde scores \pm sd op een 4-punts schaal *).

\begin{tabular}{|c|c|c|c|c|}
\hline & $\begin{array}{l}\text { Alle opleiders } \\
\text { + assistenten }\end{array}$ & $\begin{array}{l}\text { Opleiders } \\
\mathrm{U}+\mathrm{L}+\mathrm{A}\end{array}$ & $\begin{array}{l}\text { Opleiders } \\
\mathrm{U}+\mathrm{L}\end{array}$ & $\begin{array}{l}\text { Assistenten } \\
\mathrm{U}+\mathrm{L}\end{array}$ \\
\hline Farmacotherapie & $2.74 \pm 1.08$ & $2.48 \pm 1.12$ & $2.09 \pm 1.10$ & $2.94 \pm 0.97$ \\
\hline Juridische kennis & $2.66 \pm 1.09$ & $2.67 \pm 1.14$ & $2.89 \pm 1.13$ & $2.53 \pm 1.07$ \\
\hline Gestructureerd probleemoplossen & $2.41 \pm 1.16$ & $2.55 \pm 1.22$ & $2.78 \pm 1.17$ & $2.28 \pm 1.02$ \\
\hline Omgaan met klachten & $2.38 \pm 1.03$ & $2.61 \pm 0.98$ & $2.41 \pm 0.94$ & $1.82 \pm 0.88$ \\
\hline Onderscheiden van hoofd- en bijzaken & $2.37 \pm 1.08$ & $2.52 \pm 1.01$ & $2.61 \pm 0.98$ & $2.23 \pm 1.20$ \\
\hline Verslagleggen & $2.22 \pm 1.12$ & $2.44 \pm 1.05$ & $2.50 \pm 1.04$ & $1.61 \pm 0.98$ \\
\hline Medische kennis & $2.14 \pm 1.21$ & $2.37 \pm 1.18$ & $2.72 \pm 1.13$ & $2.00 \pm 1.28$ \\
\hline Probleem definiëren & $1.94 \pm 1.11$ & $2.19 \pm 1.18$ & $2.17 \pm 1.15$ & $1.56 \pm 0.92$ \\
\hline Overgang naar zelfstandigheid & $1.94 \pm 1.21$ & $1.96 \pm 1.16$ & $2.22 \pm 1.22$ & $1.83 \pm 1.29$ \\
\hline Gestructureerd consult voeren & $1.94 \pm 1.13$ & $1.92 \pm 1.16$ & $2.12 \pm 1.22$ & $1.76 \pm 1.09$ \\
\hline Onderscheid maken acuut - niet acuut & $1.90 \pm 1.04$ & $2.08 \pm 1.13$ & $2.06 \pm 1.20$ & $1.72 \pm 0.96$ \\
\hline Overzicht houden over afdeling & $1.87 \pm 0.99$ & $1.68 \pm 0.90$ & $1.88 \pm 0.96$ & $2.38 \pm 1.02$ \\
\hline Onderwijs geven & $1.83 \pm 1.01$ & $1.72 \pm 0.89$ & $1.75 \pm 0.86$ & $1.83 \pm 1.10$ \\
\hline Beroepsperspectief & $1.73 \pm 0.96$ & $1.74 \pm 0.90$ & $1.72 \pm 0.96$ & $1.67 \pm 1.08$ \\
\hline Moment van supervisor raadplegen & $1.71 \pm 1.02$ & $1.81 \pm 1.14$ & $1.72 \pm 1.13$ & $1.50 \pm 0.70$ \\
\hline Poliklinisch werken & $1.69 \pm 0.97$ & $1.81 \pm 1.07$ & $1.89 \pm 1.08$ & $1.47 \pm 0.62$ \\
\hline Samenwerken & $1.59 \pm 0.98$ & $1.70 \pm 0.99$ & $1.56 \pm 0.78$ & $1.50 \pm 1.04$ \\
\hline Heelkundige vaardigheden & $1.48 \pm 0.93$ & $1.54 \pm 1.02$ & $1.73 \pm 1.16$ & $1.47 \pm 0.87$ \\
\hline Overige vaardigheden & $1.44 \pm 0.87$ & $1.60 \pm 1.04$ & $1.75 \pm 1.06$ & $1.13 \pm 0.34$ \\
\hline \multicolumn{5}{|l|}{ Indicatie stellen voor } \\
\hline intercollegiaal consult & $1.15 \pm 0.46$ & $1.04 \pm 0.19$ & $1.06 \pm 0.24$ & $1.35 \pm 0.70$ \\
\hline
\end{tabular}

* Score 1= geen verbetering nodig; 2 = verbetering gewenst met lage prioriteit; $3=$ verbetering gewenst met middelmatige prioriteit; $4=$ verbetering gewenst met hoge prioriteit.

** $\mathrm{U}=\mathrm{UMC}$ Utrecht; L= LUMC; A= AMC, Amsterdam. 
onderwijsvormgeving. Hieruit zijn algemene suggesties voor verbetering gedestilleerd die weergegeven zijn binnen het kader van het 'Raamplan 2001 Artsopleiding' (zie tabel 2: voor een volledig overzicht kan contact worden opgenomen met de corresponderend auteur). ${ }^{7}$ Het valt op dat vooral verbetering gewenst wordt in algemene vaardigheden, zoals het onderscheiden van hoofd- en bijzaken, het formuleren van de essentie, prioriteren, gestructureerd werken, communicatieve vaardigheden en verslagleggen. Tabel 3 geeft suggesties voor opleiders die hieruit zijn afgeleid.

Invulling van een hypothetisch extra jaar Alle opleiders en arts-assistenten hebben suggesties gedaan voor de invulling van een (hypothetisch) extra jaar studie, dat erop gericht zou zijn om studenten/basisartsen beter toegerust aan de betreffende specialisatie te laten beginnen. De suggestie die het meest frequent en met de meeste nadruk gedaan werd is het klinisch laten werken van studenten met eigen verant-

Tabel 2. Suggesties voor verbetering geplaatst binnen kader van eindtermen Raamplan 2001 Artsopleiding.

\begin{tabular}{|c|c|c|}
\hline \multicolumn{2}{|c|}{$\begin{array}{l}\text { Paragrafen in Raamplan } 2001 \\
\text { Artsopleiding }\end{array}$} & \multirow[b]{2}{*}{ Voorgestelde verbeteringen } \\
\hline Eindtermen & Profiel basisarts & \\
\hline \multirow[t]{2}{*}{ Medisch } & $\begin{array}{l}\text { Proces medisch } \\
\text { probleemoplossen }\end{array}$ & $\begin{array}{l}\text { - Probleemstelling definiëren: hoofd- en bijzaken scheiden, } \\
\text { prioriteren, essentie formuleren, analyseren, reduceren, } \\
\text { hulpvraag duidelijk krijgen. } \\
\text { - Gestructureerd werken. } \\
\text { - Ziektebeloop en therapie. } \\
\text { - Verslagleggen, overdragen. }\end{array}$ \\
\hline & $\begin{array}{l}\text { Brede basiskennis- } \\
\text { en vaardigheden }\end{array}$ & $\begin{array}{l}\text { - Farmacologie, kindergeneeskunde, dermatologie, sociale } \\
\text { geneeskunde, radiologie, acute geneeskunde. } \\
\text { - Structuur gezondheidszorg. } \\
\text { - Communicatieve vaardigheden, samenwerken, communicatie } \\
\text { afstemmen op de ontvanger. } \\
\text { - Leiding geven. } \\
\text { - Visite lopen. } \\
\text { - Reanimeren. }\end{array}$ \\
\hline Wetenschappelijk & $\begin{array}{l}\text { Wetenschappelijk } \\
\text { gevormd }\end{array}$ & $\begin{array}{l}\text { - EBM. } \\
\text { - Elke stap van medisch proces evalueren. } \\
\text { - Gestructureerd informatie overdragen. }\end{array}$ \\
\hline Persoonlijk & $\begin{array}{l}\text { Juiste attitude } \\
\text { Flexibel }\end{array}$ & $\begin{array}{l}\text { - Gestructureerd werken. } \\
\text { - Zelfinzicht en zelfmanagement. } \\
\text { - Verantwoordelijkheid en zelfstandigheid. } \\
\text { - Meerdere dingen tegelijk doen. } \\
\text { - Stressbestendigheid. }\end{array}$ \\
\hline $\begin{array}{l}\text { Maatschappij en } \\
\text { gezondheids- } \\
\text { zorgsysteem }\end{array}$ & $\begin{array}{l}\text { Kent wettelijke } \\
\text { bevoegdheid en } \\
\text { bekwaamheid }\end{array}$ & $\begin{array}{l}\text { - Medisch juridische kennis. } \\
\text { - Organisatie gezondheidszorg. } \\
\text { - Omgaan met klachten. }\end{array}$ \\
\hline
\end{tabular}


Tabel 3. Suggesties voor opleiders.

- Stimuleren tot nadenken i.p.v. gegevens opsommen (geen volledigheid verlangen).

- Dwingen de essentie te formuleren.

- Co-assistenten er actiever bij betrekken. Voortdurend vragen naar (onderbouwing van) behandelplannen.

- Meer nadruk op behandelplan en minder op diagnostiek.

- Feedback geven.

- 'Klinische blik' expliciteren.

- Meer uniformiteit in begeleiding co-assistenten.

- Sfeer creëren waarin fouten besproken kunnen worden.

- Eigen fouten bespreken.

- Uitwisseling tussen academische, perifere en HAG-docenten.

- Bestendigen i.p.v afleren van in studie aangeleerde vaardigheden (bijvoorbeeld EBM).

woordelijkheid en onder goede supervisie. Bij $74 \%$ van de opleiders en bij $72 \%$ van de arts-assistenten werd dit punt genoemd. De vormgeving ervan werd aangeduid als een goed begeleid AGNIO-schap of een oudste co-schap. De term 'semi-arts', die in het rapport 'De arts van straks'8 genoemd wordt, dekt goed de lading als term voor de co-assistent in het laatste jaar van de basisopleiding, het schakeljaar. Als doelstellingen werden genoemd:

- Geleidelijke overgang naar zelfstandigheid, waarbij theorie vertaald wordt naar praktijk.

- Dokter leren zijn: handelingsbekwaam worden, rol van dokter ontwikkelen, medische verantwoordelijkheid voelen, leren omgaan met acute situaties.

- Gefundeerd een keuze maken voor een vervolgopleiding.

Ook kwam het idee van een 'brugklas' naar voren, eventueel in een paar hoofdrichtingen, waarbij zowel de opleiders als de arts-assistenten de geschiktheid voor een bepaald vak kunnen beoordelen. Een andere mogelijkheid voor het hypothetische extra jaar is het werken als poortarts om klinische ervaring op te doen, hetgeen voor veel vervolgopleidingen nut- tige ervaring kan opleveren. Ook extramuraal werken werd genoemd als mogelijkheid. Ter ondersteuning van het zelfstandige klinische werk werden genoemd:

- Communicatieve vaardigheden: door 39\% van de opleiders werd voorgesteld om hier aandacht aan te besteden, terwijl dit onderwerp door arts-assistenten niet genoemd werd.

- Onderwijs: zoveel mogelijk binnen een klinische context, gericht op vermeerdering van medische kennis. 19\% van de opleiders en $33 \%$ van de arts-assistenten zou dat in een extra jaar aan bod laten komen. Er is behoefte aan onderricht in basale vakken, waarbij de verbinding met de kliniek duidelijk is. Een voorbeeld hiervan is het zuur-base evenwicht in de context van een patiënt met ontregelde diabetes mellitus type 1 .

- Wetenschappelijke vorming: werd door $26 \%$ van de opleiders en door $22 \%$ van de arts-assistenten genoemd als waardevol element in een extra jaar.

Een volledig overzicht van alle suggesties voor de invulling van een hypothetisch extra jaar zijn op aanvraag beschikbaar bij de eerste auteur. 


\section{Conclusie}

Het onderzoek levert aanknopingspunten op voor verbetering van de aansluiting van de studie geneeskunde op vervolgopleidingen. Hoewel de studie is uitgevoerd voordat landelijk werd aanbevolen een schakeljaar in de medische opleiding op te nemen, ${ }^{8}$ kan de studie goed in dit licht gelezen worden, omdat zij gericht is op een optimale overgang van basisopleiding naar specialisatie met de vraag 'wat kan daarin beter?'. Tot de onderwerpen die met hoge prioriteit verbetering behoeven behoort de farmacotherapie. Meer in het algemeen vindt men dat het accent in de studie geneeskunde teveel ligt op het diagnostische proces en te weinig op het behandelplan. Ook de aandacht voor medisch-juridische kennis en het omgaan met klachten wordt als onvoldoende ervaren. Deze onderwerpen moeten aan de orde komen binnen een klinische context met eigen verantwoordelijkheid, ofwel tijdens het laatste deel van de studie ofwel in het eerste deel van de vervolgopleiding.

Verder is de mate waarin beginnende arts-assistenten gestructureerd te werk gaan voor verbetering vatbaar. Onder deze noemer vallen onder meer het scheiden van hoofd- en bijzaken, het stellen van prioriteiten en het analyseren en voeren van een gestructureerd spreekkamergesprek. Ook goede verslaglegging is een reflectie van gestructureerd denken en werken. Er is op het punt van gestructureerd werken zelfs voorgesteld om studenten er voor aanvang van hun studie op te selecteren; het betreft immers een kernkwaliteit van artsen.

Medische kennis staat op de zevende plaats. Studenten hebben goede opzoekvaardigheden, maar de parate kennis kan beter. De noodzaak om medisch technische vaardigheden te verbeteren was gering, omdat die snel en gericht tijdens de vervolgopleiding aangeleerd kunnen worden. Hetzelfde geldt voor het aanvragen en uitvoeren van een intercollegiaal consult.

Opvallend waren de geringe verschillen tussen de subgroepen: tussen arts-assistenten en opleiders, tussen de regio's Amsterdam, Utrecht en Leiden en tussen academische en perifere ziekenhuizen. De gelijkgestemdheid tussen opleiders en arts-assistenten kan op een werkelijk verschil berusten, maar kan ook verklaard worden door het feit dat de opleiders de te interviewen arts-assistenten zelf geselecteerd hadden.

De overeenstemming tussen de geïnterviewden kan ook zijn veroorzaakt door gelijkenis van de basiscurricula. De vragen in het interview hebben betrekking op klinische competenties van de arts en deze kunnen het beste geleerd worden in een curriculum dat ruime mogelijkheden biedt tot zelfstandig klinisch werk. Hoewel het Amsterdamse curriculum met een oudste co-schap al een grote stap in die richting is ${ }^{9}$ en in andere curricula nog verdergaande voorbereidingen getroffen worden voor dergelijke stages, ${ }^{10}$ is er behoefte aan meer zelfstandig werk. Dit blijkt ook uit de invulling van een hypothetisch extra jaar, waarbij door $73 \%$ van de geïnterviewden zelfstandig klinisch werken werd genoemd met taken en verantwoordelijkheden, met goede supervisie en met veel feedback. Het leren vanuit het perspectief 'deze patiënt is mijn verantwoordelijkheid, ik moet dit probleem oplossen' zal studenten stimuleren om zich de gewenste kennis, vaardigheden en professioneel gedrag eigen te maken en te integreren tot klinische competenties. De geringe verschillen tussen Amsterdam, Leiden en Utrecht maken niettemin een voorzichtige extrapolatie van de onderzoeksgegevens naar andere medische faculteiten mogelijk. 


\section{Dankbetuiging}

Het Centraal College Medische Specialismen (CCMS) heeft ten behoeve van dit onderzoek een deel van een VWS-subsidie voor de modernisering van de specialistenopleiding ter beschikking gesteld.

\section{Literatuur}

1. LeGrand-van den Bogaard MJM, Rooijen APN van, editors. De zorg van morgen - flexibiliteit en samenhang. Rapport van de Commissie Implementatie Opleidingscontinuüm en Taakherschikking. Den Haag: Ministerie van VWS; juli 2003.

2. Centraal College Medische Specialismen. Modernisering van de medisch specialistische opleidingen nu ter zake! Studiedag CCMS 2000. Utrecht: CCMS; 2000. Rapport CCMS 01-601.

3. Hermans LMLHA, Borst E. Brief van 9 november 2000 aan de Voorzitter van de Tweede Kamer als reactie op de motie Melkert c.s.

4. Halfwegrapportages werkgroepen $1 \mathrm{t} / \mathrm{m} 6$. Concept tussenrapportage van het project Medisch Opleidingscontinuüm. Utrecht; 21 januari 2002.

5. Lagaaij MB. Continuïteit in basis- en vervolgopleiding. Medisch Contact 1999;45(4):129.

6. Cate ThJ ten, Lagaaij MB, Blijham GH. Het zesde jaar van de artsopleiding als schakeljaar. Med Contact 2001;56(12):455-8.

7. Metz JCM, Verbeek-Weel AMM, Huisjes HJ. Raamplan 2001 Artsopleiding; bijgestelde eindtermen van de artsopleiding. Nijmegen: Mediagroep; 2001.
8. Meijboom-de Jong B, Schmit Jongbloed LJ, Willemsen MC, editors. De arts van straks - een nieuw medisch opleidingscontinuüm. Utrecht: KNMG/ DMW-VSNU/VAZ/NVZ/LCVV; oktober 2002.

9. Cate ThJ ten, Danner SA, Swinkels JA, editors. Blauwdruk vernieuwing co-assistentschappen AMC. Amsterdam: Onderwijsinstituut Geneeskunde AMC; september 1997.

10. Braak EWTM ter, editor. Jaar 6 als schakeljaar: de kroon op Cru'99 - Blauwdruk. Utrecht: Onderwijsinstituut UMC Utrecht; mei 2003.

\section{De auteurs:}

Mw. dr. H.E. Westerveld, internist, is werkzaam bij de afdeling Interne Geneeskunde, UMC Utrecht.

Mw. drs. L. Bos-Onderstal, huisarts, is werkzaam bij de afdeling Huisartsgeneeskunde, LUMC.

Mw. dr. E.W.M.T. ter Braak, internist, is werkzaam bij de afdeling Interne Geneeskunde, UMC Utrecht.

Drs. H.L. Hendrix is directeur Onderwijs en Studiezaken, afdeling Onderwijs en Studiezaken, LUMC.

Dr. M.B. Lagaaij, chirurg (n.p.), is werkzaam bij de afdeling Onderwijs en Studiezaken, LUMC.

Prof. dr. Th.B. Voorn, huisarts, is werkzaam bij het Onderwijsinstituut, UMC Utrecht.

Prof. dr. Th.J. ten Cate is medisch onderwijskundige en wetenschappelijk directeur van het Onderwijsinstituut, UMC Utrecht.

Correspondentieadres:

Dr. H.E. Westerveld, Afdeling Interne Geneeskunde, UMC Utrecht, Huispost G02.228, Postbus 85500, 3508 GA Utrecht, tel:030-2503985, h.e.westerveld@med.uu.nl.

\section{Summary}

Introduction: The aim of this study was to explore how the transition from medical school to postgraduate specialty training might be improved.

Material and methods: Thirty heads of clinical departments and 18 postgraduate trainees in the regions of Utrecht, Amsterdam and Leiden were interviewed. Their opinions were sought about the need for improvement of the training in 20 clinical competencies. In addition they were asked to give suggestions for the content and format of a hypothetical, additional curriculum year, aimed at improving the transition from medical school to medical specialty training.

Results: The need for improvement was felt strongest with respect to pharmacotherapy, medical legal issues, a structured approach to problem solving and dealing with complaints and errors. Clinical skills and consultation of colleagues ranked lowest among the priority list of skills in need of improvement. When asked for suggestions for improvement, the interviewees mentioned general skills, such as discriminating between principal and secondary issues, problem analysis, prioritising, structuring tasks, communication skills and reporting. Independence and responsibility were frequently mentioned as potential targets for improvement.

Conclusion: This study yielded many suggestions for improvement of the transition from medical school to specialty training. Important issues are general skills and independence with responsibilities. (Westerveld HE, Bos-Onderstal L, Braak EWTM ter, Hendrix HL, Lagaaij MB, Voorn ThB, Ten Cate ThJ. Transition from undergraduate to graduate medical education. Dutch Journal of Medical Education 2004;23(1):15-22.) 